\title{
Misleading New Entity in Tumors of Kidney: A Case Report and Literature Review*
}

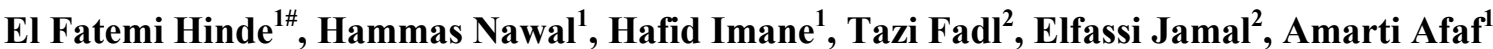 \\ ${ }^{1}$ Department of Pathology, Hassan II Teaching Hospital, Fez, Morocco \\ ${ }^{2}$ Department of Urology, Hassan II Teaching Hospital, Fez, Morocco \\ Email: "hinde0012@hotmail.com
}

Received July 16, 2012; revised August 24, 2012; accepted September 7, 2012

\begin{abstract}
Introduction: Mucinous tubular and spindle cell carcinomas (MTSCC's) are recently described rare type of renal cell carcinoma (RCC). They may have morphological similarities to papillary RCC (papRCC) and in our case to carcinoma collecting ducts of Bellini. Case Report: We report a rare case of renal tumor, mucinous tubular and spindle cell carcinoma in a 56-year-old woman. The tumor, located in the left kidney, was well circumscribed. MTSCC's are characterized by small, elongated tubules lined by cuboidal cells and/or cords of spindled cells separated by pale mucinous stroma. Discussion: MTSCC is a rare type of renal cell carcinoma. Pathologists should be aware of the histological spectrum of MTSCCs to ensure an accurate diagnosis. Careful attention to the presence of a spindle cell population may be helpful in the differential diagnosis in tumors with predominant compact tubular growth.
\end{abstract}

Keywords: Renal Carcinoma; Mucinous Tubular and Spindle Cell Carcinoma; CD10; Immunohistochemistry

\section{Introduction}

Mucinous tubular and spindle cell carcinoma (MTSCC) of the kidney is a novel neoplastic entity of renal cell carcinoma (RCC) that has only recently been recognized. It was first described in 1998 and specifically described by Parwani et al. [1] a series of MTSCCs as a separate entity. The recent World Health Organization classification of renal tumors officially included MTSCC as a separate category [2]. Because MTSCC has only recently been recognized, there are no more than 80 cases reported in the literature [1,3-5]. In the present report, we report a case of MTSCC that showed unusual morphologic features of spindle cell predominance, psammomatous calcification, and depletion of extracellular mucin.

\section{Case Report}

A 56-year-old woman had macroscopic hematuria for 1 month. She had no medical or family history of any malignancy. All of his laboratory data were within the normal ranges. Computed tomography revealed a huge renal mass in the left kidney (Figure 1). No metastatic lesions or lymph node enlargement were noted. The gross tumor had dimensions of $12.5 \times 12.0 \times 10 \mathrm{~cm}$ and was located in the inferior pole, confined to the renal parenchyma, and surrounded by a pseudocapsule. The tumor was well

\footnotetext{
${ }^{*}$ The authors declare no conflict of interest.

${ }^{\#}$ Corresponding author.
}

circumscribed and showed a variegated, grayish white cut surface with hemorrhagic and necrotic areas. Renal vein invasion and perinephric fat involvement were not identified. The nephrectomy specimen was extensively sampled. Sections were fixed in $10 \%$ neutral-buffered formalin and processed for light microscopy via conventional methods. Routine processing for histologic examination included paraffin embedding, sectioning, and standard staining with hematoxylin and eosin safran. Morphologically, the tumor showed predominantly spindle cells arranged in fascicles composed of bland oval to spindle nuclei with fine chromatin and small nucleoli (Figure 2). There were tubular structures variably lined by small cuboidal cells with eosinophilic cytoplasm and focal psammoma bodies. Approximately $95 \%$ of the tumor was composed of spindle cell carcinoma cells that merged with areas of tubular structures. There was no significant atypia, increased mitotic activity, or vascular invasion identified. An interesting finding was focal psammomatous calcification. There was depletion of extracellular mucinous material throughout the sections (Figure 2). The scant mucinous material was not appreciated by hematoxylin and eosin stain but it required mucin stain to be recognized. Some foamy histiocytes and a inflammatory cells identified in the stroma with necrotic and hemorrahgic areas. Three diagnoses were suspected in these histological patterns: inflammatory pseudo-tumours, carcinoma of collecting ducts of bellini 


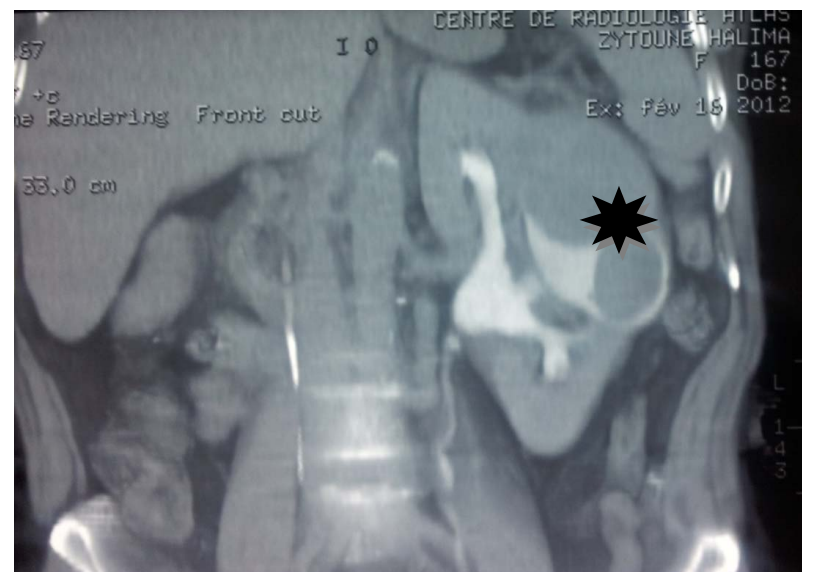

Figure 1. Computed tomography revealed a huge renal mass in the left kidney.

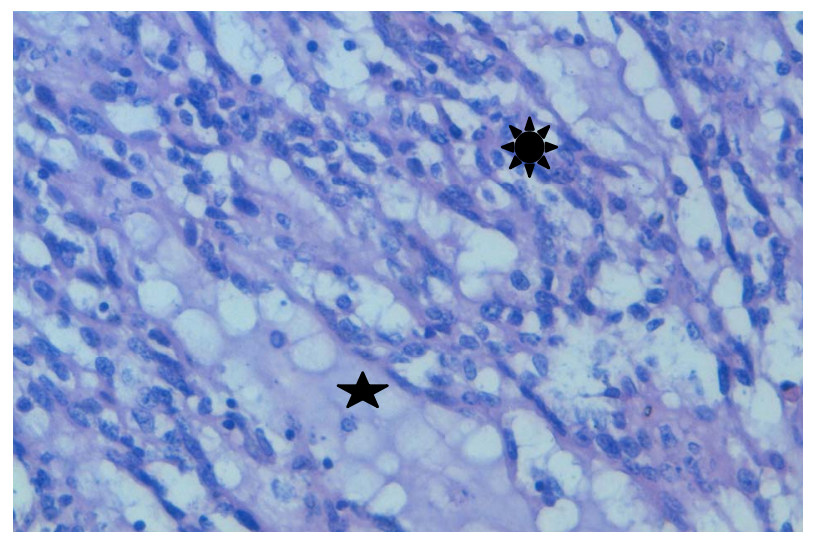

Figure 2. Hematoxylin Eosin Safran $($ HES) $\times 40$. * Tumor showed spindle cells arranged in fascicles composed of bland oval to spindle nuclei with fine chromatin and small nucleoli. ^ Extracellular mucinous material.

and mucinous tubular and spindle cell carcinoma. Mucinous stroma was reactive for alcian blue and periodic acid-Schiff stains. Immunohistochemical studies demonstrated that tumor cells showed diffuse, intense staining for epithelial membrane antigen, cytokeratin (CK) 7 , $8 / 18$ and focally vimentin. The tumor cells were completely negative for CK20 and CD10.

\section{Discussion}

Although there is a relatively small number of series detailing this Renal Cell Carcinoma, its unique morphological features and clinical presentation are sufficiently characteristic that the World Health Organization has recognized it as a distinct clinicopathologic entity. Much is known about this tumor, but its histomorphological features, histogenesis, and relationship to other renal cell tumors remains undefined. MTSCC's is preferentially observed in adults. Patients' age ranged from 21 to 81 years, with a mean and median of 55.8 and 58.5 years, respectively. The male to female ratio was $1 / 3[4,6]$. The right kidney was more involved [5]. Their diameter varied between 1.8 and $17 \mathrm{~cm}$ (mean diameter, $6 \mathrm{~cm}$ ) [4]. The tumor is usually present as an asymptomatic mass, often found on ultrasound. Occasionally, the patients may present with flank pain or hematuria [7]. The tumors were generally confined (pT1 or pT2) in more than $80 \%$ of the cases $[4,5,8]$. The radiological appearance of mucinous tubular and spindle cell carcinoma is diverse and therefore indistinguishable from the more common subtypes of renal cell carcinoma [9]. Grossly, tumors are mainly circumscribed and can be large and are usually contained within the renal capsule. Histologically, tumors show tubules or cords of cuboidal cells that transition to sheets of spindle cells against a basophilic mucinous matrix. The epithelial nuclei are round to ovoid and bland, and mitotic figures are rare. Either spindle or tubular components can predominate, and mucin can be sparse or absent. Foamy macrophages, heterotopic bone, and psammomatous calcification are described as well as, rarely, necrosis [6]. Small numbers of cases with high nuclear grade (Fuhrman grade 3) are reported [10]. True sarcomatoid change has also rarely been described [11,12], with authors noting, in addition to classic MTSCC morphology, high-grade spindled areas resembling fibrosarcoma and undifferentiated pleomorphic sarcoma, with necrosis and a high proliferation index. MTSCC tumors have a complex immunoprofile. Shen et al. [8] demonstrated the expression of differentiation markers of proximal tubules, which were renal cell carcinoma marker antigen (RCC Ma) (92\%), a-Methylacyl-COA racemase (AMACR) (92\%), CD15 (Leu M1) (67\%) as well as CK7, which is known to stain the distal tubules (92\%). Positive staining was seen with markers that were found in the collecting duct epithelium, including EMA and peanut agglutinin (PNA) [4]. The remaining markers, which are more specific to the proximal tubules, are CD10, the collecting duct (aquaporin 3) and the kidneyspecific cadherin expressed in only a few cases $[8,13]$. The vimentine positivity was infrequent. It is observed in $14 \%-40 \%$ of the cases $[4,8,13]$. The proliferative rate (MIB-1) was low, suggesting a low proliferation activity, $[4,14]$ a finding that may in part explain the low malignancy of this tumor type. Mucinous tubular and spindle cell carcinoma with spindle cell predominance may simulate a variety of benign or malignant spindle cell renal tumors. In cases with limited diagnostic material, such as fine-needle biopsy specimens, it is important to recognize that this spindle cell morphology may occur in MTSCC and may necessitate differential diagnostic consideration from other spindle cell neoplasms [15]. The major differential diagnosis of the mucin-poor spindle cell predominance MTSCC is the sarcomatoid differentiation (SD) that has been recognized to arise in all types 
of RCC since the Heidelberg classification of renal cell tumors was published in 1997 [16]. The presence of SD in RCC represents high-grade transformation that has a deleterious effect on prognosis. Tumors containing SD have a decreased 5 -year survival rate from $79 \%$ to $22 \%$ in stage-matched patient cohorts; tumors containing more than $50 \%$ SD have an even worse prognosis [17]. Mucinous tubular and spindle cell carcinoma lacks large, hyperchromatic/pleomorphic nuclei or significant mitotic activity and had a much more uniform architectural pattern. Ki-67 can be helpful in demonstrating the low proliferation rate in MTSCC. The widening spectrum of MTSCC in recent years has led to the description of atypical, sarcomatoid and metastatic cases as well [10, 14]. It therefore seems more important to be aware of such morphological changes in MTSCC diagnosis and employ IHC analysis [18,19] However, there are also cases that are extremely similar to papRCC in the differential diagnosis $[5,8]$. Fluorescent in situ hybridization or comparative genomic hybridization studies may take the place of IHC investigation in the differential diagnosis. These studies have reported multiple chromosomal losses including 1, 4, 6, 8, 11, 13, 14, 18, 22 instead of chromosomal additions $[4,13,20,21]$. The chromosome 3 losses that are typical for clear RCC have not been found.

In summary, we report a case of mucin poor spindle cell predominance MTSCC with psammomatous calcification that expands the histologic spectrum encountered in these tumors that may overlap with other renal neoplasms and can be a diagnostic dilemma. Awareness of variable morphologic variants of MTSCC is important to avoid a misdiagnosis.

\section{Acknowledgements}

The authors thank Dr F. Mege-Lechevallier and Dr S. Collardeau Franchon for their help in the diagnosis.

\section{REFERENCES}

[1] A. V. Parwani, A. N. Husain, J. I. Epstein, J. B. Beckwith and P. Argani, "Lowgrade Myxoid Renal Epithelial Neoplasms with Distal Nephron Differentiation," Human Pathology, Vol. 32, No. 5, 2001, pp. 506-512. doi:10.1053/hupa.2001.24320

[2] J. N. Eble, G. Sauter, J. I. Epstein and I. A. Sesterhenn, "World Health Organization Classification of Tumors. Pathology and Genetics of Tumors of the Urinary System and Male Genital Organs," International Agency for Research on Cancer (IARC), Lyon, 2004.

[3] O. Hes, M. Hora, D. M. Perez-Montiel, S. Suster, R. Curik, L. Sokol, et al., "Spindle and Cuboidal Renal Cell Carcinoma, a Tumour Having Frequent Association with Nephrolithiasis: Report of 11 Cases including a Case with Hybrid Conventional Renal Cell Carcinoma/Spindle and Cuboidal Renal Cell Carcinoma Components," Histopa- thology, Vol. 41, No. 6, 2002, pp. 549-555. doi:10.1046/j.1365-2559.2002.01515.x

[4] C. Rakozy, G. E. Schmahl, S. Bogner and S. Storkel, "Low-Grade Tubularmucinous Renal Neoplasms: Morphologic, Immunohisto-Chemical, and Genetic Features," Modern Pathology, Vol. 15, No. 11, 2002, pp. 1162-1171. doi:10.1097/01.MP.0000031709.40712.46

[5] G. P. Paner, J. R. Srigley, A. Radhakrishnan, et al., "Immunohistochemical Analysis of Mucinous Tubular and Spindle Cell Carcinoma and Papillary Renal Cell Carcinoma of the Kidney: Significant Immunophenotypic Overlap Warrants Diagnostic Caution," American Journal of Surgical Pathology, Vol. 30, No. 1, 2006, pp. 13-19. doi:10.1097/01.pas.0000180443.94645.50

[6] S. W. Fine, P. Argani, A. DeMarzo, et al., "Expanding the Histologic Spectrum of Mucinous Tubular and Spindle Cell Carcinoma of the Kidney," American Journal of Surgical Pathology, Vol. 30, No. 12, 2006, pp. 1554-1560. doi:10.1097/01.pas.0000213271.15221.e3

[7] R. Srigley, "Mucinous Tubular and Spindle Cell Carcinoma," In: J. N. Eblc, G. Sauter, J. I. Epstein and I. A. Sesterhenn, Eds., World Health Organization Classification of Tumours: Pathology and Genetics. Tumours of Urinary System and Male Genital Organs, Lyon, IARC Press, 2004, p. 40.

[8] S. S. Shen, J. Y. Ro, P. Tamboli, et al., "Mucinous Tubular and Spindle Cell Carcinoma of Kidney Is Probably a Variant of Papillary Renal Cell Carcinoma with Spindle Cell Features," Annals of Diagn Pathology, Vol. 11, No. 1, 2007, pp. 13-21. doi:10.1016/j.anndiagpath.2006.09.005

[9] V. A. Sahni, M. S. Hirsch, C. A. Sadow and S. G. Silverman, "Mucinous Tubular and Spindle Cell Carcinoma of the Kidney: Imaging Features," Cancer Imaging, Vol. 5, No. 12, 2012, pp. 66-71. doi:10.1102/1470-7330.2012.0008

[10] N. Kuroda, O. Hes, M. Michal, et al., "Mucinous Tubular and Spindle Cell Carcinoma with Fuhrman Nuclear Grade 3: A Histological, Immunohistochemical, Ultrastructural and FISH Study," Histological Histopathology, Vol. 23, No. 12, 2008, pp. 1517-1523.

[11] N. Pillay, P. K. Ramdial, K. Cooper, et al., "Mucinous Tubular and Spindle Cell Carcinoma with Aggressive Histomorphology-A Sarcomatoid Variant," Human Pathology, Vol. 39, No. 6, 2008, pp. 966-969. doi:10.1016/i.humpath.2007.10.006

[12] S. Bulimbasic, D. Ljubanovic, R. Sima, et al., "Aggressive High-Grade Mucinous Tubular and Spindle Cell Carcinoma," Human Pathology, 2009, Vol. 40, No. 6, pp. 906-907. doi:10.1016/j.humpath.2009.03.004

[13] S. Ferlicot, Y. Allory, E. Compérat, et al., "Mucinous Tubular and Spindle Cell Carcinoma: A Report of 15 Cases and Review of the Literature," Virchows Archive, Vol. 477, No. 6, 2005, pp. 978-983. doi:10.1007/s00428-005-0036-x

[14] P. Brandle, A. K. Lie, A. Bassarova, et al., "Genomic Aberrations in Mucinous Tubular and Spindle Cell Renal Cell Carcinomas," Modern Pathology, Vol. 19, No. 2, 2006, pp. 186-194. doi:10.1038/modpathol.3800499 
[15] S. A. Gadre, S. K. Math, K. A. Elfeel and H. Farghaly, "Cytology of a Sarcomatoid Renal Cell Carcinoma with Unusual Coexpression of S-100 Protein: A Case Report, Review of the Literature and Cytologic-Histologic Correlation," Diagn Cytopathology, Vol. 37, No. 3, 2009, pp. 195-198. doi:10.1002/dc.21003

[16] G. Kovacs, M. Akhtar, B. J. Beckwith, P. Bugert, C. S. Cooper, B. Delahunt, et al., "The Heidelberg Classification of Renal Cell Tumours," Journal of Pathology, Vol. 183, No. 2, 1997, pp. 131-133. doi:10.1002/(SICI)1096-9896(199710)183:2<131::AID-P ATH931>3.0.CO;2-G

[17] M. de Peralta-Venturina, H. Moch, M. Amin, P. Tamboli, S. Hailemariam, M. Mihatsch, et al., "Sarcomatoid Differentiation in Renal Cell Carcinoma: A Study of 101 Cases," American Journal of Surgical Pathology, Vol. 25, No. 3, 2001, pp. 275-284. doi:10.1097/00000478-200103000-00001

[18] L. D. Truong and S. S. Shen, "Immunohistochemical
Diagnosis of Renal Neoplasms," Archive Pathological of Lab Medicine, Vol. 135, No. 12, 2011, pp. 92-109.

[19] S. Sen, B. Sars, A. Simsir, E. Kmal and E. Gokmen, "Böbrekte Kitle Nedeniyle Yapılan Iğne Kor Biyopsileri ve Tanı Zorlukları," Turk Patoloji Derg, Vol. 26, No. 2, 2010, pp. 5-18.

[20] P. Cossu-Rocca, J. N. Eble, B. Delahunt, S. Zhang, G. Martignoni, M. Brunelli and L. Cheng, "Renal Mucinous Tubular and Spindle Carcinoma Lacks the Gains of Chromosomes 7 and 17 and Losses of Chromosome Y That Are Prevalent in Papillary Renal Cell Carcinoma," Modern Pathology, Vol. 19, No. 14, 2006, pp. 488-493. doi:10.1038/modpathol.3800565

[21] P. Argani, G. J. Netto and A. V. Parwani, "Papillary Renal Cell Carcinoma with Low-Grade Spindle Cell Foci: A Mimic of Mucinous Tubular and Spindle Cell Carcinoma," American Journal of Surgical Pathology, Vol. 32, No. 9, 2008, pp. 1353-1359. doi:10.1097/PAS.0b013e31816a1c34 